\title{
ON THE POSSIBILITY OF INDIRECT DETERMINATION OF THE GLASS TRANSITION TEMPERATURE OF PROTEINS FROM VISCOSITY MEASUREMENTS AND AVRAMOV'S MODEL
}

\author{
KAROL MONKOS \\ Department of Biophysics, Medical University of Silesia, H. Jordana 19, 41-808 Zabrze 8, Poland
}

Received November 13, 2014; accepted December 11, 2014; published online December 12, 2014

\begin{abstract}
The paper presents the results of viscosity determinations on aqueous solutions of hen egg-white lysozyme, bovine $\beta$-lactoglobulin, human and porcine immunoglobulin IgG at a wide range of concentrations and at temperatures ranging from $5^{\circ} \mathrm{C}$ to $55^{\circ} \mathrm{C}$. Viscositytemperature dependence of the proteins solutions is analyzed based on a formula resulting from the Avramov's model. One of the parameters in the Avramov's equation is the glass transition temperature $\mathbf{T}_{\mathrm{g}}$. It turns out that for all studied proteins, the $\mathbf{T g}$ of the solution increases with increasing concentration. To determine the glass transition temperature of the dry protein $T_{\mathrm{g}, \mathrm{p}}$, a modified form of the Gordon-Taylor equation is used. This equation gives the relationship between $T_{g}$ and the concentration of the solution, and $T_{g, p}$ and a parameter dependent on the strength of protein-solvent interaction are fitting parameters. Thus determined the glass transition temperature for the studied dry proteins is in the range from $227.3 \mathrm{~K}$ (for bovine $\beta$-lactoglobulin) to $260.6 \mathrm{~K}$ (for hen eggwhite lysozyme).
\end{abstract}

\section{INTRODUCTION}

The proteins in the solutions may occur in native form only in a specific $\mathrm{pH}$ range, and relatively narrow temperature range. Freezing point of the solution and the temperature of protein denaturation effectively define boundaries from the side of low and high temperatures, respectively. In this temperature range, the temperature dependence of solution viscosity can receive based on several models of viscous flow of liquid. To the most important can include free volume model (Vinogradov \& Malkin, 1980), a modified Arrhenius model (Monkos 1996) and the Avramov's model (Avramov, 1998). These models allow to obtain different types of information on the test system, because they consider the mechanism of flow in different way. In the present paper, only Avramov's model is taken into consideration. Based on this model, one can obtain three-parameter equation binding viscosity with temperature. One of the parameters in this equation is the glass transition temperature $\mathrm{T}_{\mathrm{g}}$.

As a result of the cooling process, liquids crystallize. However, if the liquid is supercooled below the melting point, it then solidify forming a non-crystalline state which is usually called the glass. This process occurs at a characteristic temperature called the glass transition temperature (Martinez \& Angell, 2001). For temperatures above $T_{g}$, anharmonic motions of bonded and nonbonded groups of atoms in proteins dominate, as in the liquid state. At temperatures below $\mathrm{T}_{\mathrm{g}}$, in turn, harmonic motions predominate, as in the solid state. In other words, the glass transition temperature of the protein is the temperature in which its properties change from liquid-like to solid-like. In the literature of recent years can be seen increasing interest to glass transition phenomenon of biopolymers such as proteins or polysaccharides (Grasmeijer et al., 2013; Marsh et al., 2013; Khatkar et al., 2013; Roughton et al., 2012; García et al., 2012; Panagopoulou et al., 2011; Rodríguez Furlán et al., 2011; Hernández et al., 2011; Khodadadi et al., 2010; Jansson \& Swenson, 2010). The glass transition temperature of proteins is determined primarily using calorimetric and rheological measurements and dielectric spectroscopy. In the present paper $\mathrm{T}_{\mathrm{g}}$ for dry hen egg-white lysozyme (HEWL), bovine $\beta$-lactoglobulin (BLG), human immunoglobulin $\mathrm{IgG}(\mathrm{HIgG})$ and porcine immunoglobulin $\mathrm{IgG}(\mathrm{PIgG})$ has been obtained on the basis of viscosity measurements of aqueous solutions of these proteins, from Avramov's model and modified Gordon-Taylor equation.

HEWL is an enzyme that acts as a glycoside hydrolaze. It is a small globular protein with a molecular mass $\mathrm{M}=14.32 \mathrm{kDa}$ (Squire \& Himmel, 1979) and well known structure (Smith et al., 1993). In solution it can be treated as prolate ellipsoid of revolution with the main axes $4.5 \mathrm{~nm}$ and $3 \mathrm{~nm}$ (Monkos, 1997). In addition, infrared spectra analysis of HEWL in solution 
and crystalline form showed that in both cases its structure is very similar (Hadden et al, 1995). HEWL is used as a model protein in various biophysical and biochemical studies. Its structure, dynamics, and - in particular - the hydrodynamic properties have been examined by different experimental techniques (Monkos, 2011 and references therein).

BLG is the major whey protein of the cow's milk. It is also small, globular protein consisting of 162 amino acid residues and having a molecular mass of $18.155 \mathrm{kDa}$ (Oreccini et al, 2001). It is able to bind a wide range of ligands, aromatic molecules, alkanone species and is thought to be a member of the lipocalin family of hydrophobic carrier molecules (Kuwajima et al, 1996). At physiological $\mathrm{pH}$ BLG forms dimers, in which the monomers are noncovalently linked (Aymard et al, 1996). BLG is used as a model protein in different studies of folding, stability and self-association.

The immunoglobulins can be divided into five major classes: IgG, IgA, IgM, IgD and IgE. They constitute about $20 \%$ of the total plasma proteins. $\operatorname{IgG}$ immunoglobulins, in turn, constitute approximately $75 \%$ of them (Goodman, 1991). IgG molecules with a molecular mass of $156 \mathrm{kDa}$, consist of four polypeptide chains - two identical light chains and two identical heavy chains. They are folded in three globular structures - two $\mathrm{F}_{\mathrm{ab}}$ fragments and one $\mathrm{F}_{\mathrm{c}}$ fragment (AlLazikani et al, 1997). As a result, the entire molecule looks like the letter $\mathrm{T}$ or $\mathrm{Y}$. This means that the immunoglobulins IgG are non-globular proteins.

\section{MATERIALS}

Highly purified HEWL, BLG and PIgG were purchased from Sigma Chemical Co. and HIgG from Polish Chemical Reagents factories and were used without further purification for all the measurements. From crystalline form, the proteins were dissolved in distilled water and the solutions thus obtained were filtered through a paper filter to remove possible undissolved dust particles. These solutions were stored in a refrigerator until just prior to viscometry measurements, when they were wormed from $5^{\circ} \mathrm{C}$ to $55^{\circ} \mathrm{C}$. The $\mathrm{pH}$ values of such prepared samples were measured by using $\mathrm{pH}$ meter. The $\mathrm{pH}$ values of such solutions of immunoglobulins - in the whole range of measured concentrations - were close to their isoelectric points and were as follows: 5.6 for $\mathrm{HIgG}$ and 5.9 for PIgG. The isoelectric point for $\mathrm{HIgG}$ is in the range $(5.8-6.6)$ (Young, 1963). The $\mathrm{pH}$ values of HEWL and BLG solutions were, in turn, outsider of their isoelectric points, and were as follows: 7.0 for HEWL and 7.2 for BLG. The isoelectric point for HEWL is in the range (11- 11.2) (Young, 1963) and is equal to 5.6 for BLG (Roth et al, 2000). The $\mathrm{pH}$ values for different concentrations differed slightly from each other, and the values given above are the average values.

\section{VISCOMETRY}

The viscosity measurements of aqueous solutions of test proteins were carried out using an Ubbelohde-type capillary microviscometer with a flow time for water of $28.5 \mathrm{~s}$ at $25^{\circ} \mathrm{C}$. Microviscometer was placed in a water bath whose temperature was stabilized with an accuracy of $\pm 0.1^{\circ} \mathrm{C}$. All measurements were performed using the same viscometer. Measurements began after a few minutes of delay that the system may reach a state of equilibrium. Flow times were measured with an accuracy of $\pm 0.1 \mathrm{~s}$. For most concentrations the viscosity measurements were conducted from $5^{\circ} \mathrm{C}$ to $55^{\circ} \mathrm{C}$ by steps of $5^{\circ} \mathrm{C}$. Limitation of viscosity measurements to the temperature of $55^{\circ} \mathrm{C}$ results from the fact that above this temperature the solutions flow times increase with increasing temperature, which means that the proteins are gradually denatured.

The densities of solutions were measured by using weighing method, while the proteins concentrations were determined by a dry weight method in which solutions were dried at high temperatures for several hours. Viscosity measurements were made for individual proteins in the following ranges: from $17 \mathrm{~kg} / \mathrm{m}^{3}$ to 285 $\mathrm{kg} / \mathrm{m}^{3}$ for $\mathrm{HIgG}$, from $28 \mathrm{~kg} / \mathrm{m}^{3}$ to $223 \mathrm{~kg} / \mathrm{m}^{3}$ for $\mathrm{PIgG}$, from $25 \mathrm{~kg} / \mathrm{m}^{3}$ to $343 \mathrm{~kg} / \mathrm{m}^{3}$ for HEWL. Viscosity measurements of BLG solutions were made for concentrations in the range from $20 \mathrm{~kg} / \mathrm{m}^{3}$ to $444 \mathrm{~kg} / \mathrm{m}^{3}$. However - in the further analysis - viscosity data were used only for the solutions above the concentration of $119 \mathrm{~kg} / \mathrm{m}^{3}$, since only above this concentration and the temperature range used herein, BLG molecules are present in the form of dimers (Aymard et al, 1996).

\section{RESULTS AND DISCUSSION}

According to the Avramov's model molecules in a flowing liquid jump from one equilibrium state to the other. During the jumps molecule has to overcome some energy barrier (or activation energy), which may be different for different jumps. It is further assumed that the frequency of these jumps is different for different molecules and it is subject to the Poisson distribution. This allows calculate the average frequency of these jumps. Finally, Avramov's model assumes that the viscosity of the liquid is inversely proportional to the mean frequency of these jumps. On the basis of these assumptions, one can get the relation between the viscosity and temperature of the liquid. For solutions, where viscosity is dependent on both temperature and concentration, this dependence has the following form: 


$$
\eta(c, T)=\eta_{\infty}(c) \exp \left[\frac{\Theta(c)}{T}\right]^{\alpha(c)},
$$

where $\eta_{\infty}(\mathrm{c}), \Theta(\mathrm{c})$ and $\alpha(\mathrm{c})$ are parameters dependent on the concentration.

To adjust the viscosity - obtained from Avramov's relation - to the experimental values of viscosity numerical values of the parameters $\eta_{\infty}(\mathrm{c}), \Theta(\mathrm{c})$ and $\alpha(\mathrm{c})$ are required. The relevant calculations were performed using a non-linear regression procedure in the computational statistical program. Figure 1 shows the viscosity measurement results for all the proteins tested here, but - for each protein - only for a single selected concentration. Curves exhibit fit to the experimental points in accordance with relation (1), with parameters values obtained from the above-mentioned method. As seen this relation then gives a perfect fit over the whole range of measured temperatures. Equally good fit is obtained for all the concentrations of the studied proteins.

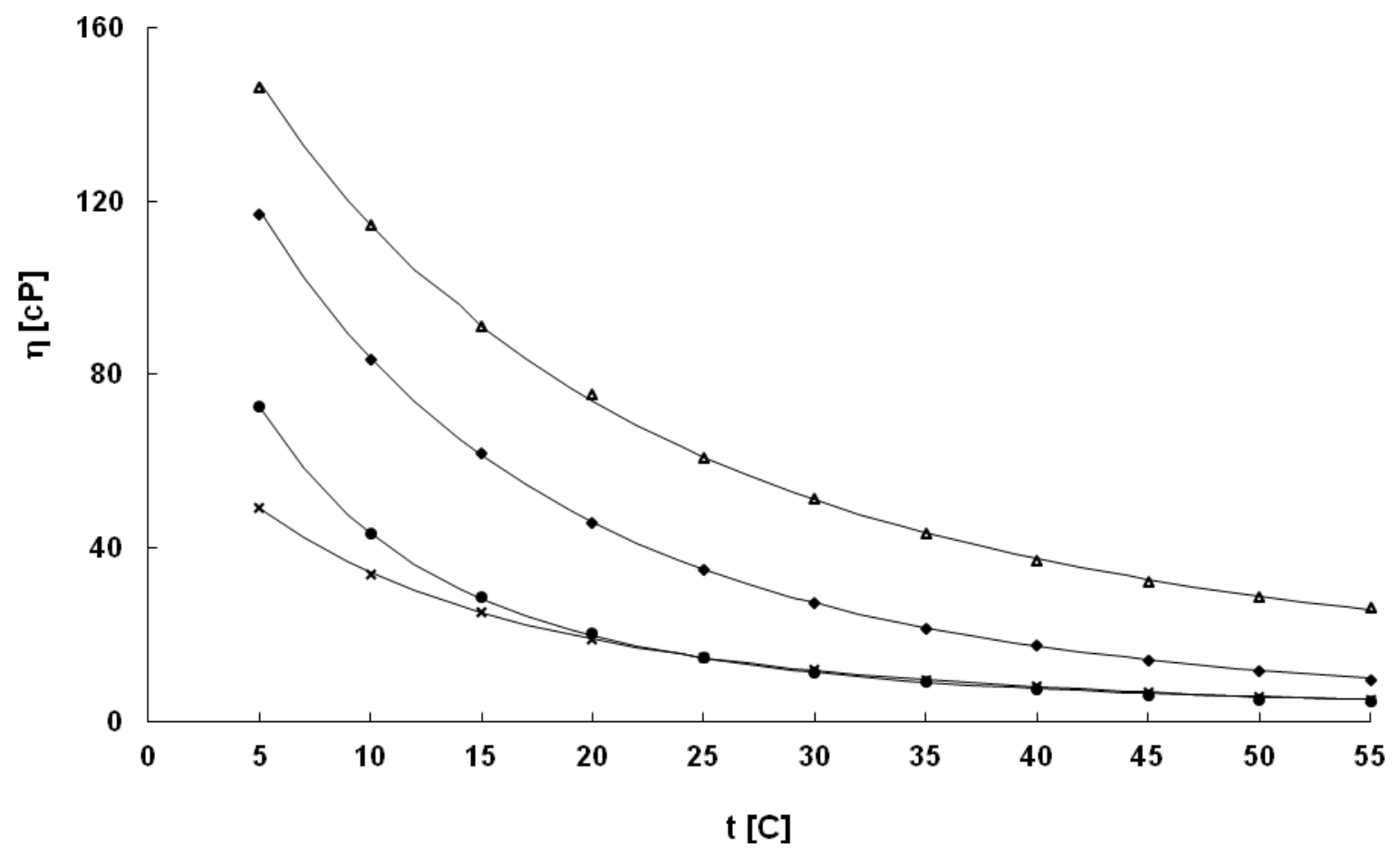

Fig. 1. Temperature dependence of the viscosity of $\operatorname{BLGL}(\Delta), \operatorname{HIgG}(\bullet), \operatorname{HEWL}(\bullet)$, and $\operatorname{PIgG}(\times)$ aqueous solutions for concentrations: $\mathrm{c}=$ $430,433,343$ and $210 \mathrm{~kg} / \mathrm{m}^{3}$, respectively. The curves show the fit obtained by using equation (1) with the parameters given in Table 1.

Table 1. The parameters of equation (1) for the selected concentrations of the studied proteins solutions.

\begin{tabular}{lcccc}
\hline & Protein & $\eta_{\infty}(\mathrm{c})[\mathrm{cP}]$ & $\Theta(\mathrm{c})[\mathrm{K}]$ & $\alpha(\mathrm{c})$ \\
\hline $\mathrm{HIgG}$ & $\left(\mathrm{c}=433 \mathrm{~kg} / \mathrm{m}^{3}\right)$ & 0.398 & 461.3 & 3.437 \\
PIgG & $\left(\mathrm{c}=210 \mathrm{~kg} / \mathrm{m}^{3}\right)$ & 1.192 & 351.8 & 5.591 \\
HEWL $\left(\mathrm{c}=343 \mathrm{~kg} / \mathrm{m}^{3}\right)$ & 2.437 & 317.9 & 9.157 \\
BLGL $\left(\mathrm{c}=430 \mathrm{~kg} / \mathrm{m}^{3}\right)$ & 4.637 & 372.7 & 4.241 \\
\hline
\end{tabular}

From the point of view of purposes of this work, the most interesting parameter is the $\Theta(c)$. According to the Avramov's model $\Theta(c)=T_{g}(c) \varepsilon^{1 / \alpha(c)}$, where $T_{g}(c)$ is the glass transition temperature of the solution and the quantity $\varepsilon$ means the ratio of the activation energy corresponding to its value at the maximum of the probability distribution function to a dispersity of the activation energy. The glass transition temperature of the solution depends on the glass transition temperature of the individual components. The glass transition temperature of binary mixtures is considered in a classical thermodynamic approach by Gordon and Taylor (Gordon \& Taylor, 1952). According to this approach $\mathrm{Tg}$ of the mixture depends on the $\mathrm{Tg}$ of 
components, and the strength of the interaction between them. For a mixture of protein and water, GordonTaylor formula can be written in the following way:

$$
T_{g}=\frac{w_{p} T_{g, p}+k w_{w} T_{g, w}}{w_{p}+k w_{w}}
$$

in which $\mathrm{w}_{\mathrm{p}}$ and $\mathrm{w}_{\mathrm{w}}$ denote weight fractions of the protein and water, and $\mathrm{T}_{\mathrm{g}, \mathrm{p}}$ and $\mathrm{T}_{\mathrm{g}, \mathrm{w}}$ are glass- transition temperature of the dry protein and water, respectively. The parameter $\mathrm{k}$ is related to the strength of proteinwater interaction. Couchmann showed that this parameter is equivalent to the ratio of the heat capacity changes of the pure components at Tg (Couchmann, 1978).

To be able to apply the Gordon-Taylor equation for solutions, the weight fractions should be expressed by the concentration of the solution. According to the definition: $\mathrm{w}_{\mathrm{p}}=\mathrm{m}_{\mathrm{p}} /\left(\mathrm{m}_{\mathrm{p}}+\mathrm{m}_{\mathrm{w}}\right), \mathrm{w}_{\mathrm{w}}=\mathrm{m}_{\mathrm{w}} /\left(\mathrm{m}_{\mathrm{p}}+\mathrm{m}_{\mathrm{w}}\right)$ and $\mathrm{m}_{\mathrm{p}}$ and $\mathrm{m}_{\mathrm{w}}$ are masses of the dissolved protein and water in a solution, respectively. The mole numbers of the dissolved protein and water, in turn, are defined as: $\mathrm{N}_{\mathrm{p}}=$ $\mathrm{m}_{\mathrm{p}} / \mathrm{M}_{\mathrm{p}}, \mathrm{N}_{\mathrm{w}}=\mathrm{m}_{\mathrm{w}} / \mathrm{M}_{\mathrm{w}}$ and $\mathrm{M}_{\mathrm{p}}$ and $\mathrm{M}_{\mathrm{w}}$ are their molecular masses. It follows that $\mathrm{w}_{\mathrm{p}}=\mathrm{N}_{\mathrm{p}} \mathrm{M}_{\mathrm{p}} /\left(\mathrm{N}_{\mathrm{p}} \mathrm{M}_{\mathrm{p}}+\mathrm{N}_{\mathrm{w}} \mathrm{M}_{\mathrm{w}}\right)$ and $\mathrm{w}_{\mathrm{w}}=\mathrm{N}_{\mathrm{w}} \mathrm{M}_{\mathrm{w}} /\left(\mathrm{N}_{\mathrm{p}} \mathrm{M}_{\mathrm{p}}+\mathrm{N}_{\mathrm{w}} \mathrm{M}_{\mathrm{w}}\right)$. Given the above, and using the definition of the molar fractions of the dissolved protein and water: $X_{p}=N_{p} /\left(N_{p}+N_{w}\right)$ and $X_{w}$ $=\mathrm{N}_{\mathrm{w}} /\left(\mathrm{N}_{\mathrm{p}}+\mathrm{N}_{\mathrm{w}}\right)$ one can transform equation (2) to the following form:

$$
T_{g}=\frac{X_{p} M_{p} T_{g, p}+k X_{w} M_{w} T_{g, w}}{X_{p} M_{p}+k X_{w} M_{w}} .
$$

The molar fraction of the dissolved protein can be expressed by the concentration of the solution in the following way (Monkos, 1996):

$$
X_{p}=\frac{c}{\rho_{w} \frac{M_{p}}{M_{w}}-c\left(\rho_{w} \frac{M_{p}}{M_{w}} \xi-1\right)},
$$

where $\rho_{\mathrm{w}}$ and $\xi$ denote the water density and the effective specific volume of a protein, respectively, and c is the solution concentration in $\mathrm{kg} / \mathrm{m}^{3}$. The effective specific volume is a coefficient of proportionality between the effective molar volume and the molar mass of a macrosolute. Since the sum of the molar fractions of the individual components of the solution is equal to 1 , so $X_{w}=1-X_{p}$. Taking this into account - after substituting equation (4) into the formula (3) - we get Gordon-Taylor equation in the form convenient for use in the case of solutions:

$$
T_{g}(c)=\frac{c\left(T_{g, p}-k \rho_{w} \xi T_{g, w}\right)+k \rho_{w} T_{g, w}}{c\left(1-k \rho_{w} \xi\right)+k \rho_{w}}
$$

The effective specific volume of all studied proteins has been experimentally determined earlier and it is equal to: $2.6 \times 10^{-3} \mathrm{~m}^{3} / \mathrm{kg}$ for HEWL (Monkos, 1997), $1.27 \times 10^{-}$ ${ }^{3} \mathrm{~m}^{3} / \mathrm{kg}$ for BLG (Monkos, 2006), $2.25 \times 10^{-3} \mathrm{~m}^{3} / \mathrm{kg}$ for HIgG (Monkos, 2009), 2.71 $\times 10^{-3} \mathrm{~m}^{3} / \mathrm{kg}$ for $\mathrm{PIgG}$ (Monkos, 2009).

The glass transition temperature of the bulk water has been determined by a number of authors. The values obtained are slightly different from each other and the most frequently cited value is $\mathrm{T}_{\mathrm{g}, \mathrm{w}}=136 \mathrm{~K}$ (Sartor et al, 1994; Johari et al, 1987; Hallbrucker et al, 1989; Teeter et al, 2001; Katkov \& Levine, 2004).

As mentioned above, the glass transition temperature of the solution $\mathrm{T}_{\mathrm{g}}(\mathrm{c})$ is related to the parameters of Avramov's model $\Theta(c)$ and $\alpha(\mathrm{c})$ by the relation: $\Theta(\mathrm{c})=$ $\mathrm{T}_{\mathrm{g}}(\mathrm{c}) \varepsilon^{1 / \alpha(\mathrm{c})}$. For the calculation of $\mathrm{T}_{\mathrm{g}}(\mathrm{c})$ - at a given concentration - in addition to the values of $\Theta(c)$ and $\alpha(\mathrm{c})$ the value of the parameter $\varepsilon$ is needed. It turns out that - according to equation (5) - $\mathrm{T}_{\mathrm{g}}(\mathrm{c})$ increases monotonically with increasing concentration. The value of the parameter $\varepsilon$ should be chosen so that in the limit of zero concentration $\mathrm{T}_{\mathrm{g}}(\mathrm{c})$ was equal to the $\mathrm{T}_{\mathrm{g}, \mathrm{w}}$. In this way determined the values of parameter $\varepsilon$ are given in Table 2. In the Avramov's work value of the parameter $\varepsilon$ was determined for a number of inorganic liquids. The author received the values of $\varepsilon$ in the range $(25.1-35.1)$ with the average value $(30.5 \pm 2)$. As can be seen from Table 2 the values of $\varepsilon$ obtained for HEWL and BLG are very close to the lower limit of the range.

Table 2. The glass transition temperature $\mathrm{T}_{\mathrm{g.p}}$ and the parameters $\varepsilon$ and $\mathrm{k}$ of the Avramov's model for the studied proteins.

\begin{tabular}{lccc}
\hline \multicolumn{1}{c}{ Protein } & $\varepsilon$ & $\mathrm{T}_{\mathrm{g}, \mathrm{p}}[\mathrm{K}]$ & $\mathrm{k}$ \\
\hline HIgG & 20.2 & $241.7 \pm 5.6$ & $0.4603 \pm 0.061$ \\
PIgG & 20.85 & $240.9 \pm 4.5$ & $0.2592 \pm 0.032$ \\
HEWL & 23.6 & $260.6 \pm 5.6$ & $1.237 \pm 0.14$ \\
BLGL & 24.25 & $227.3 \pm 13$ & $1.250 \pm 0.36$ \\
\hline
\end{tabular}


From the relation $\Theta(\mathrm{c})=\mathrm{T}_{\mathrm{g}}(\mathrm{c}) \varepsilon^{1 / \alpha(\mathrm{c})}$ - with known values of the parameters $\varepsilon, \Theta(c)$ and $\alpha(\mathrm{c})$ - one can calculate the $\mathrm{T}_{\mathrm{g}}(\mathrm{c})$ values for each concentration of the studied proteins. This way calculated values of $\mathrm{T}_{\mathrm{g}}(\mathrm{c})$ have been presented in Figures 2 and 3. Since the effective specific volume of the proteins and the glass transition temperature of water are known, the only unknown parameters in the modified Gordon-Taylor equation (5) are the glass transition temperature of the dry protein and the parameter $\mathrm{k}$.
The function of equation (5) can be fit to the experimental points if $\mathrm{T}_{\mathrm{g}, \mathrm{p}}$ and $\mathrm{k}$ are treated as the fitting parameters. Such calculations were performed using non-linear regression procedure in the computational statistical program. Thus calculated $\mathrm{T}_{\mathrm{g}, \mathrm{p}}$ and $\mathrm{k}$ are given in Table 2. As shown in Figure 2 and 3 the function of modified Gordon-Taylor equation gives a good fit to the $\mathrm{T}_{\mathrm{g}}(\mathrm{c})$ values obtained in the above-described manner.

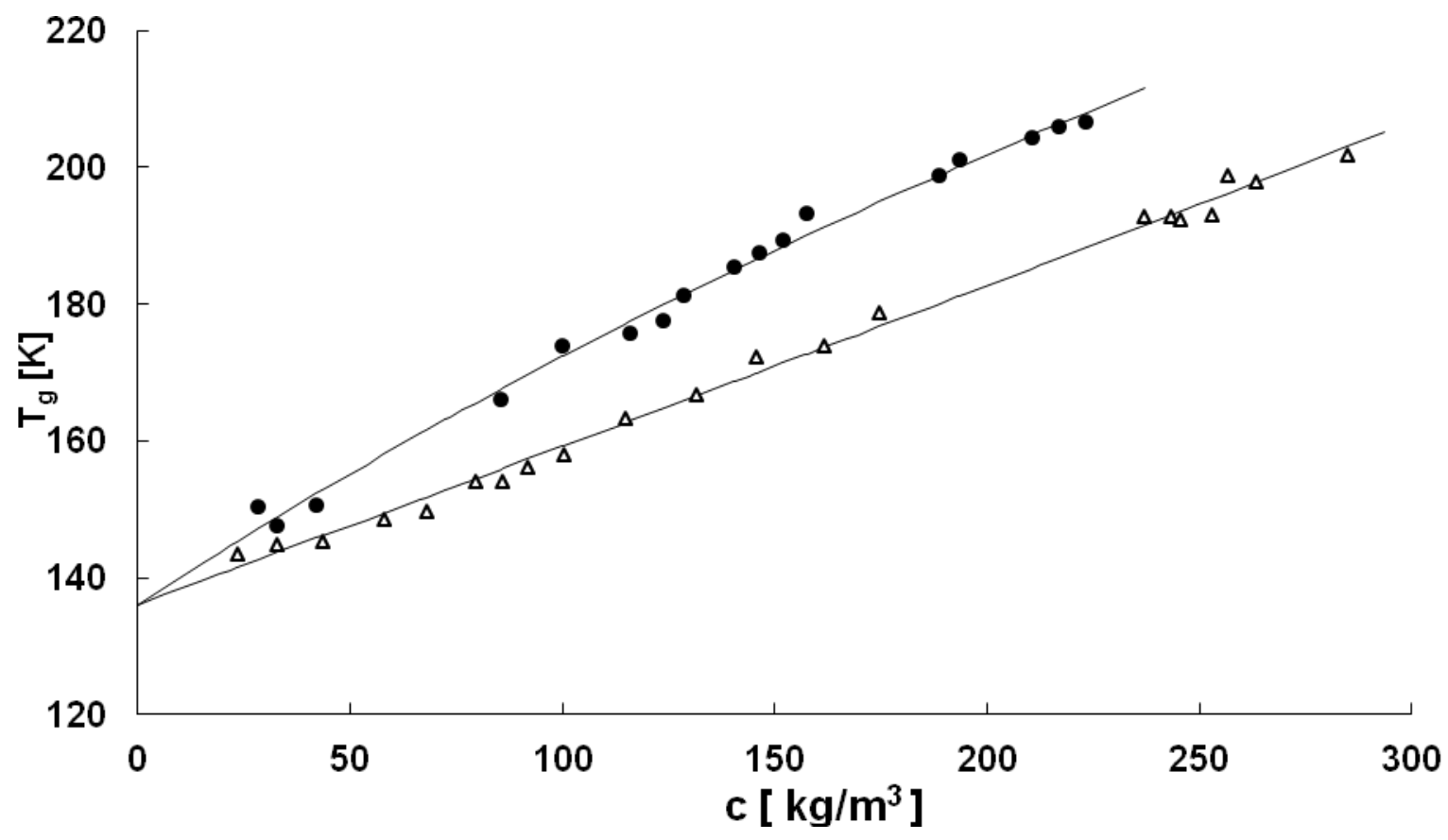

Fig. 2. Plot of the glass-transition temperature $\mathrm{T}_{\mathrm{g}}(\mathrm{c})$ of the $\operatorname{PIgG}(\bullet)$ and $\operatorname{HIgG}(\Delta)$ aqueous solutions versus concentration. The curves show the fit according to relation (5) with $\mathrm{T}_{\mathrm{g}, \mathrm{w}}=136 \mathrm{~K}$ and with the parameters shown in Table 2 and in the text above.

To fulfill its physiological functions biological macromolecules, and in particular, globular and nonglobular proteins, must demonstrate a structural flexibility. This may be demonstrated among others by examining the proteins in solution by viscometry method (Monkos, 2000, 2004,2013). This flexibility of proteins causes that all interactions cause a slight displacements of atoms, resulting in the change of protein conformation. Change of the protein conformation, in turn, causes that slightly changes also its energy. This can be described by the conformational energy landscape like in glasses. It is now widely accepted view that the protein molecule may be present in one of the many isoenergetic conformational substates, corresponding to the valleys in the protein energy landscape (Frauenfelder et al, 1991). As a result of all kinds of interactions, protein energy may vary due to transitions between the conformational substates. As the lowering of the temperature, these transitions become more slower, and in certain temperature the protein is frozen in a specific substate. This temperature is called the glass transition temperature of the protein $\mathrm{T}_{\mathrm{g}, \mathrm{p}}$. In the vicinity of the glass transition temperature a strong changes in temperature dependence of various physical quantities, such as heat capacity, density and elastic modulus are observed.

There are not too many literature data on the value of the glass transition temperature of proteins. For example, for small DNA oligonucleotide duplex $\mathrm{d}(\mathrm{CGCGCG})_{2}$ in aqueous solution - using molecular dynamic simulations method - a glass transition temperature in the range $(223$ - 234) K was obtained (Ringe \& Petsko, 2003). The results of some works indicate that the glass transition process of proteins does 
not occur at one temperature but in a wide temperature range (Morozov \& Gevorkian, 1985; Sartor et al, 1994). For example, calorimetric studies of lysozyme, myoglobine and albumin suggest the existence of a glass transition in a wide temperature range from 130 to 240 K (Morozov \& Gevorkian, 1985). The glass transition process in hydrated hemoglobin, in turn, extends from about $150 \mathrm{~K}$ up to temperature of denaturation (Sartor et $a l, 1994)$. Furthermore, the glass transition temperature for a specific protein, obtained by different methods may differ significantly from each other. For example, the glass transition temperature of myoglobin obtained by dielectric spectroscopy and differential scanning calorimetry method is in the range (190 - 210) K (Jansson \& Swenson, 2010), and as determined by the molecular dynamics simulation is $220 \mathrm{~K}$ (Steinbach \& Brooks, 1993). The above examples show that to the strict determination of the glass transition temperature of proteins would be desirable a confrontation the results from different methods.

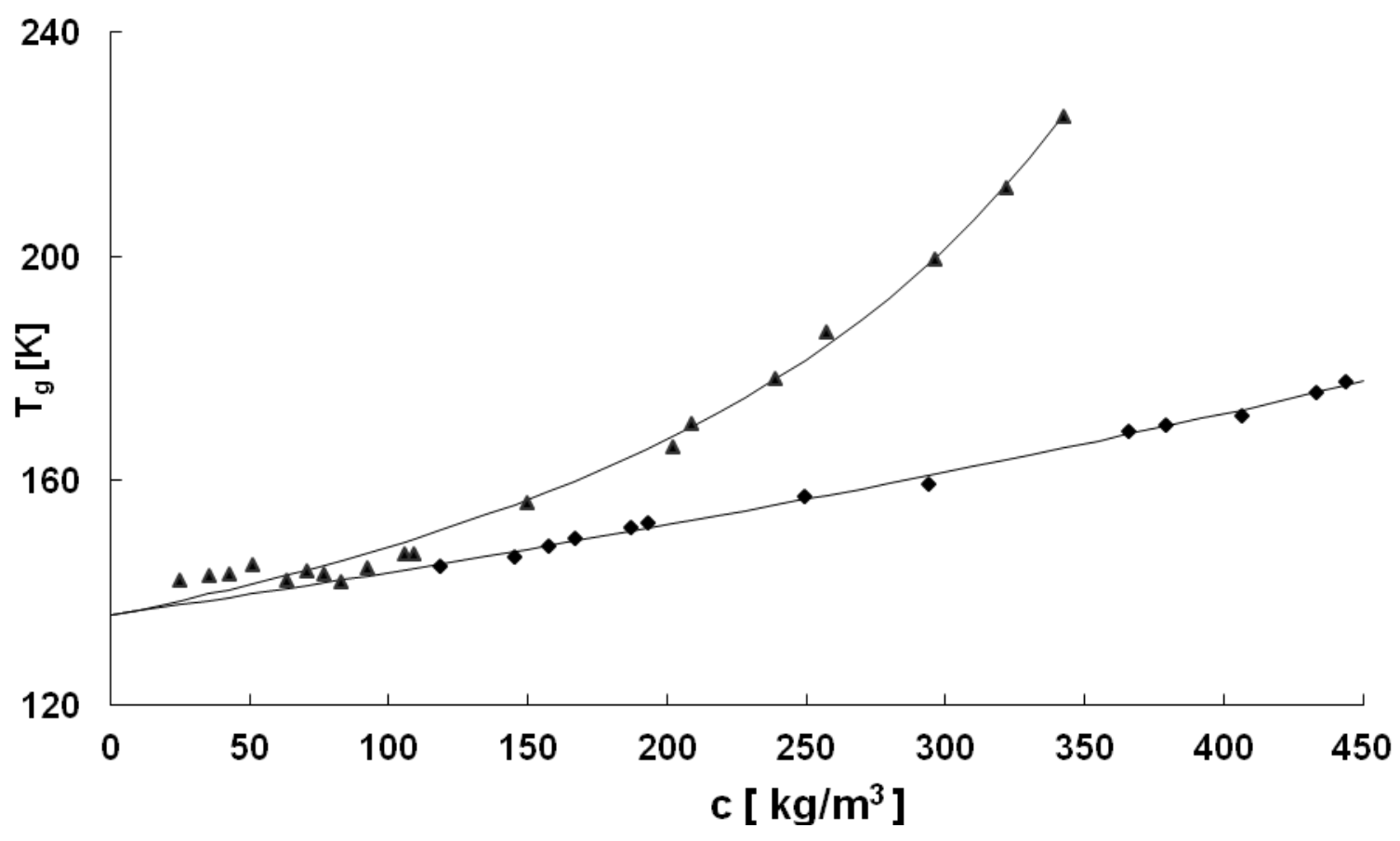

Fig. 3. Plot of the glass-transition temperature $T_{g}(c)$ of the HEWL $(\boldsymbol{\Delta})$ and BLGL $(\bullet)$ aqueous solutions versus concentration. The curves show the fit according to relation (5) with $\mathrm{T}_{\mathrm{g}, \mathrm{w}}=136 \mathrm{~K}$ and with the parameters shown in Table 2 and in the text above.

The glass transition temperatures for studied proteins solutions obtained in this work (Figures 2 and 3), are above the glass transition temperature of water $(136 \mathrm{~K})$ up to $202 \mathrm{~K}$ for $\mathrm{HIgG}, 212 \mathrm{~K}$ for PIgG, $225 \mathrm{~K}$ for HEWL and $178 \mathrm{~K}$ for BLGL. As can be seen, they lie in the range of the glass transition temperatures for the hydrated proteins reported in the literature. Moreover, comparison of the above values with the results given in Table 2 shows that the glass transition temperature of a given protein in a dry state is always higher than the glass transition temperature of this protein solutions. Unfortunately, as far as I know, there is no appropriate data in the literature concerning the glass transition temperature of proteins in the dry state.

\section{CONCLUSIONS}

Functional dependence of viscosity on temperature, resulting from Avramov's model can be used to analyze the results of viscosity measurements of globular and non-globular proteins solutions in the temperature range from $5^{\circ} \mathrm{C}$ to $55^{\circ} \mathrm{C}$. One of the three parameters found in the Avramov's equation is glass transition temperature. It depends on the concentration of the solution. For each of the studied protein, increase in concentration of solution causes a non-linear increase of $\mathrm{Tg}$. Functional dependence of the glass transition temperature of the solution on the concentration can be given on the basis of a modified form of the Gordon-Taylor equation. The glass transition temperature of the dissolved protein is 
one of the parameters of this equation. Numerical values of $\mathrm{T}_{\mathrm{g}, \mathrm{p}}$ obtained for the studied proteins are in the range from $227.3 \mathrm{~K}$ (for bovine $\beta$-lactoglobulin) to $260.6 \mathrm{~K}$ (for hen egg-white lysozyme).

\section{ACKNOWLEDGMENTS}

This work was supported by the project of MUS: KNW$1-039 / \mathrm{K} / 4 / 0$.

\section{REFERENCES}

Al.-Lazikani B., Lesk A.M., Chothia C. (1997). Standard conformations for the canonical structures of immunoglobulins. J. Mol. Biol. 273, 927-948.

Avramov I. (1998). Viscosity of glassforming melts. J. NonCryst. Solids 238, 6-10.

Aymard P., Durand D., Nicolai T. (1996). The effect of temperature and ionic strength on the dimerisation of $\beta$ lactoglobulin. Int. J. Biol. Macromol. 19, 213-221.

Couchmann P.R. (1978). A classical thermodynamic discussion of the effect of composition on glass-transition temperatures. Macromolecules 11, 117-119.

Frauenfelder H., Sligar S.G., Wolynes P.G. (1991). The energy landscapes and motions of proteins. Science 254, 1598-1603.

García L., Cova A., Sandoval A.J., Müller A.J., Carrasquel L.M. (2012). Glass transition temperatures of cassava starchwhey protein concentrate systems at low and intermediate water content. Carbohydr. Polym. 87, 1375-1382.

Goodman J.W. (1991). Immunoglobulin structure and function. [In:] Stites D.P., Terr A.I. (eds.), Basic and clinical immunology. Prentice Hall, pp. 109-121.

Gordon M., Taylor J.S. (1952). Ideal copolymers and the second-order transition of synthetic rubbers. J. Appl. Chem. 2, 493-499.

Grasmeijer N., Stankovic M., de Waard H., Frijlink H.W., Hinrichs W.L.J. (2013). Unreveling protein stabilization mechanisms: Vitrification and water replacement in a glass transition temperature controlled system. Biochim. Biophys. Acta 1834, 763-769.

Hadden J.M., Chapman D., Lee D.C. (1995). A comparison of infrared spectra of proteins in solution and crystalline forms. Biochim. Biophys. Acta 1248, 115-122.

Hallbrucker A., Mayer E., Johari G.P. (1989). The heat capacity and glass transition of hyperquenched glassy water. Phil. Mag. 60B, 179-187.

Hernández H.G., Livings S., Aguilera J.M., Chiralt A. (2011). Phase transitions of dairy proteins, dextrans and their mixtures as a function of water interactions. Food Hydrocolloids 25, 1311-1318.

Jansson H., Swenson J. (2010). The protein glass transition as measured by dielectric spectroscopy and differential scanning calorimetry. Biochim. Biophys. Acta 1804, 20-26.

Johari G.P., Hallbrucker A., Mayer E. (1987). The glass transition of hyperquenched water. Nature 330, 552-553.

Katkov I.I., Levine F. (2004). Prediction of the glass transition temperature of water solutions: comparison of different models. Cryobiology 49, 62-82.

Khatkar B.S., Barak S., Mudgil D. (2013). Effects of gliadin addition on the rheological, microscopic and thermal characteristics of wheat gluten. Int. J. Biol. Macromol. 53, $38-41$.

Khodadadi S., Malkovskiy A., Kisliuk A., Sokolov A.P. (2010). A broad glass transition in hydrated proteins. Biochim. Biophys. Acta 1804, 15-19.

Kuwajima K., Yamaya H., Sugai S. (1996). The burst-phase intermediate in the refolding of $\beta$-lactoglobulin studied by stopped-flow circular dichroism and absorption spectroscopy. J. Mol. Biol. 264, 806-822.

Marsh D., Bartucci R., Guzzi R., Sportelli L., Esmann M. (2013). Librational fluctuations in protein glasses. Biochim. Biophys. Acta 1834, 1591-1595.

Martinez L.M., Angell C.A. (2001). A thermodynamic connection to the fragility of glass-forming liquids. Nature 410, 663-667.

Monkos K. (1996). Viscosity of bovine serum albumin aqueous solutions as a function of temperature and concentration. Int. J. Biol. Macromol. 18, 61-68.

Monkos K. (1997). Concentration and temperature dependence of viscosity in lysozyme aqueous solutions. Biochim. Biophys. Acta 1339, 304-310.

Monkos K. (2000). Viscosity analysis of the temperature dependence of the solution conformation of ovalbumin. Biophys. Chem. 85, 7-16.

Monkos K. (2004). On the hydrodynamics and temperature dependence of the solution conformation of human serum albumin from viscometry approach. Biochim. Biophys. Acta 1700, 27-34.

Monkos K. (2006). On the hydrodynamics of dimeric bovine $\beta$-lactoglobulin solutions from viscometry approach. Polish J. Environ. Stud. 15, 88-90.

Monkos K. (2009). Activation energy of viscous flow for some globular and non-globular proteins obtained from viscosity measurements and modified Arrhenius equation. Ann. Acad. Med. Siles. 63, 27-38.

Monkos K. (2011). A comparison of the activation energy of viscous flow for hen egg-white lysozyme obtained on the basis of different models of viscosity f or glass-forming liquids. Curr. Top. Biophys. 34, 1-9.

Monkos K. (2013). A viscometric approach of $\mathrm{pH}$ effect on hydrodynamic properties of human serum albumin in the normal form. Gen. Physiol. Biophys. 32, 67-78.

Morozov V.N., Gevorkian S.G. (1985). Low-temperature glass transition in proteins. Biopolymers 24, 1785-1799.

Oreccini A., Paciaroni A., Bizzarri A.R., Cannistraro S. (2001). Low-frequwncy vibrational anomalies in $\beta$ lactoglobulin: contribution of different hydrogen classes reveiled by inelastic neutron scattering. J. Phys. Chem. B, 105, 12150-12156.

Panagopoulou A., Kyritsis A., Sabater i Serra R., Gómez Ribelles J.L., Shinyashiki N., Pissis P. (2011). Glass transition and dynamics in BSA-water mixtures over wide ranges of composition studied by thermal and dielectric techniques. Biochim. Biophys. Acta 1814, 1984-1996.

Ringe D., Petsko G.A. (2003). The "glass transition" in protein dynamics: what it is, why it occurs, and how to exploit it. Biophys. Chem. 105, 667-680.

Rodríguez Furlán L.T., Lecot J., Pérez Padilla A., Campderrós M.E., Zaritzky N. (2011). Effect of saccharides on glass transition temperatures of frozen and freeze dried bovine plasma protein. J. Food Engn. 106, 74-79. 
Roth S., Murray B.S., Dickinson E. (2000). Interfacial shear Rheology of aged and heat-treated $\beta$-lactoglobulin films: Displacement by nonionic surfactant. J. Agric. Food Chem. 48, 1491-1497.

Roughton B.C., Topp E.M., Camarda K.V. (2012). Use of Glass transitions in carbohydrate excipient designe for lyophilized protein formulations. Comput. Chem. Engn. 36, 208-216.

Sartor G., Mayer E., Johari G.P. (1994). Calorimetric studies of the kinetic unfreezing of molecular motions in hydrated lysozyme, hemoglobin, and myoglobin. Biophys. J. 66, 249258.

Smith L.J., Sutcliffe M.J., Redfield C., Dobson C.M. (1993). Structure of hen lysozyme in solution. J. Mol. Biol. 229, 930944.

Squire P.G., Himmel M.E. (1979). Hydrodynamics and protein hydration. Arch. Biochem. Biophys. 196, 165-177.

Steinbach P.J., Brooks B.R. (1993). Protein hydration Elucidated by molecular dynamics simulation. Proc. Natl. Acad. Sci. USA 90, 9135-9139.

Teeter M.M., Yamano A., Stec B., Mohanty U. (2001). On the Nature of a glassy state of matter in a hydrated protein: Relation to protein function. Proc. Natl. Acad. Sci. USA 98, 11242-11247.

Vinogradov G.V., Malkin A.Ya. (1980). Rheology of Polymers. Mir, Moscow, 1980.

Young E.G. (1963). Occurrence, classification, preparation And analysis of proteins. [In:] Florkin M., Stolz E.H. (eds.), Comprehensive biochemistry. Amsterdam, pp. 22. 